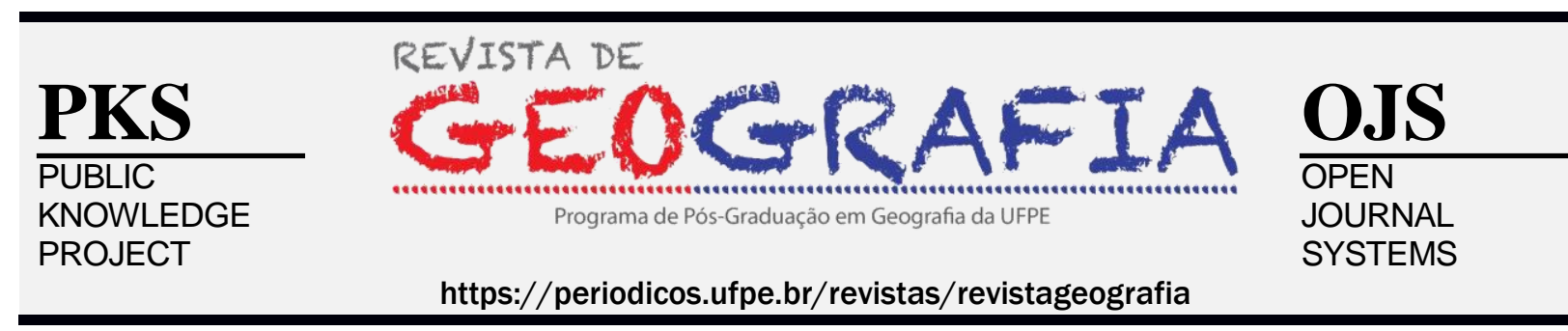

\title{
A POLÍTICA PÚBLICA DE COMPENSAÇÃO FINANCEIRA DOS RECURSOS NATURAIS
}

\author{
Francisco Kennedy Silva dos Santos ${ }^{1}$, Etevaldo Almeida Silva ${ }^{2}$ \\ ${ }^{1}$ Professor do Programa de Pós-Graduaçã̃ em Geografia da UFPE. E-mail: kennedyufpe@gmail.com \\ ${ }^{2}$ Professor do Departamento de Economia da UERN. E-mail: etevaldoalmeidasilva@ gmail.com
}

Artigo recebido em 19/10/2019 e aceito em 14/01/2020

\begin{abstract}
RESUMO
Este ensaio de natureza exploratória, constituída de duas fases: descritiva e explicativa vislumbra o interesse pelo estudo da compensação financeira, tem relação com a sua importância, como alternativa para implementação de instrumento econômico e de gestão, que contribua para o desenvolvimento social, econômico e ambiental, reduzindo os impactos negativos decorrentes da produção. Durante a pesquisa constatou-se que a compensação financeira dos recursos naturais pode ser um mecanismo utilizado para evitar a produção desordenada das externalidades negativas e por outro lado servirá como instrumento econômico que proporciona o equilíbrio equitativo do meio ambiente. Foi também possível identificar que a categoria compensação financeira, é um campo de estudo que apresenta perspectivas positivas para novas pesquisas, porque ainda se revelou pouco explorada e com necessidade de mais literatura. Se constatou também a necessidade de elaboração de um instrumental metodológico que der suporte a avaliação desta política pública.
\end{abstract}

Palavras-chave: Compesação Financeira, Políticas Públicas, Meio Ambiente.

\section{THE PUBLIC POLICY FOR FINANCIAL COMPENSATION FOR NATURAL RESOURCES}

\begin{abstract}
This exploratory essay, consisting of two phases: descriptive and explanatory, looks at the interest in the study of financial compensation, is related to its importance, as an alternative for the implementation of an economic and management instrument that contributes to social, economic and reducing the negative impacts of production. During the research it was found that the financial compensation of natural resources can be a mechanism used to avoid the disorderly production of negative externalities and on the other hand it will serve as an economic instrument that provides the equitable balance of the environment. It was also possible to identify that the financial compensation category, is a field of study that presents positive perspectives for new research, because it has still been little explored and in need of more literature. There was also a need to develop a methodological tool to support the evaluation of this public policy.
\end{abstract}

Keywords: Financial Compensation, Public Policies, Environment. 


\section{INTRODUÇÃO}

A Política Nacional de Meio Ambiente, estabelece as definiçõos e princípios de utilização racional dos recursos naturais, com foco na redução dos danos ambientais causados pelas relações antrópicas. Portanto, se fundamenta no valor econômico do serviço ambiental, oriundo da demanda da sociedade pelos recursos naturais, quando se constata a escassez pela consequência da oferta reduzida desse bem. Neste contexto, ainda se enfatiza que o surgimento de uma política pública voltada para compensação financeira dos recursos naturais, se deu em função dos desequilíbrios ambientais, resultantes das atividades humanas, estimuladas pela busca incessante do desenvolvimento econômico, com foco na utilização desordenada dos recursos naturais.

Este ensaio de natureza exploratória, constituída de duas fases: descritiva e explicativa vislumbra o interesse pelo estudo da compensação financeira, tem relação com a sua importância, como alternativa para implementação de instrumento econômico e de gestão, que contribua para o desenvolvimento social, econômico e ambiental, reduzindo os impactos negativos decorrentes da produção.

A fundamentação metodológica adotada, toma como referência, os estudos em torno dos métodos de natureza qualitativa acerca da compensação financeira dos recursos naturais. A motivação para construção aqui apresentada, se deu pelo interesse em responder ao questionamento: Quais são as políticas públicas que regulamentam a compensação financeira dos recursos naturais? Entende-se que esta indagação se consolida através da natureza de uma política pública ambiental que seja eficiente, eficaz e justa para a população do espaço que possui recursos naturais abundantes, e que são fonte de matéria prima para o desenvolvimento da produção e do bem-estar social.

\section{ASPÉCTOS CONCEITUAIS DA COMPENSAÇÃO FINANCEIRA DOS RECURSOS NATURAIS}

Nesta seção, se faz necessário destacar algumas definições e conceitos relevantes que fundamenta a categoria teórica compensação financeira, fonte de inspiração deste trabalho.

A princípio, torna-se evidente destacar o entendimento do termo denominado meio ambiente, qual seja: “...conjunto de condições, leis, influências e interações de ordem física, 
química e biológica, que permite, abriga e rege a vida em todas as suas formas" (BRASIL, 1981). Esta definição, conforme Faria (2008), está reiterada na Constituição Federal de 1988 (CF-88), quando o meio ambiente é definido: pelo meio natural constituído por solo, água, ar, flora, fauna e por outros elementos naturais que proporcionam o equilíbrio dinâmico entre os seres vivos e o meio que habitam; pelo meio ambiente cultural envolvendo o patrimônio histórico, artístico, arqueológico, paisagístico, turístico, científico e pelas ações culturais que integram as práticas sociais e as relações inerentes ao homem com a natureza; pelo meio ambiente artificial aqui está presente as edificações, equipamentos, rodovias, e outros elementos que constituem o espaço urbano e o meio ambiente do trabalho constituído pelos bens e instrumentos de natureza material e imaterial nos quais os indivíduos executam suas atividades laborais.

Uma outra definição significativa para este estudo, é a de bem ambiental. Este bem é aquele que está apresentado como de uso comum para a sociedade, portanto não pertence a nenhum indivíduo, embora haja uma particularidade tratada no direito de propriedade em que, alguns bens de natureza pública, são tratados como particulares, porém, a $\mathrm{CF} 88$, deixou evidente a proteção do meio ambiente, impondo limites ao direito de propriedade.

Além dos bens públicos e dos bens privados, a CF 88 ainda apresenta a categoria de bem difuso, cuja titularidade é diferente dos outros anteriormente citados, sendo o bem ambiental classificado nesta categoria. Este é um bem de uso comum da sociedade, cabendo ao poder público e aos indivíduos a obrigatoriedade de defende-lo e preservá-lo. Aqui, o envolvimento da sociedade no processo de desenvolvimento sustentável é garantido, bem como a prevenção dos danos ambientais, e evidentemente a responsabilização dos agentes causadores dos referidos danos. É importante destacar que a economia ambiental está preocupada em identificar e resolver o problema dos danos ambientais ou da poluição, associados ao fluxo de resíduos (THOMAS \& CALLAN, p. 19, 2010).

O termo dano ambiental é outra definição singular para o entendimento deste objeto de estudo. Portanto, o dano ambiental, conforme a maioria dos pesquisadores, é associado à poluição resultante da degradação, restringindo de forma direta o direito de uso do bem ambiental. Neste contexto, torna-se relevante identificar o causador do dano ao bem ambiental para que possa responder legalmente. Assim, é necessário identificar se estes são oriundos de poluentes naturais, ou seja, aqueles que surgem por meio de processos não artificiais da natureza, ou advindos de poluentes antropogênicos, resultantes da ação humana incluindo os resíduos associados ao consumo e á produção. 
Outro conceito relevante aqui é o de poluidor-pagador. Este determina que quem provoca poluentes antropogênicos degradando o espaço, deve assumir a responsabilidade pelos prejuízos causados ou previstos, evitando que o ônus recaia sobre a coletividade. Este princípio visa à prevenção do dano, cuja lógica é a de que estes prejuízos ambientais geram compensação financeira e sempre deverão ser mais onerosos para os causadores do que as ações de prevenção para evita-los

Destaca-se também neste conjunto de aspectos conceituais, o termo licenciamento ambiental. Ressalta-se que quando o dano ambiental é de difícil ou impossível reparação, é fundamental que o poder público institua as ações de natureza preventiva para evitar uma maior ocorrência de danos ambientais. Este fundamenta a medida mitigadora, destinada a prevenir impactos adversos ou a reduzir aqueles que não podem ser evitados.

Quando o dano ambiental já foi consumado ou quando ele é relevante para o desenvolvimento de uma atividade econômica, é implementada a medida compensatória, relacionada com o nível e intensidade dos impactos ambientais causados. Esta medida compensa os impactos ambientais negativos, destinados a compensar impactos irreversíveis que não podem ser evitados. É uma medida não necessariamente de cunho pecuniário, de responsabilidade dos causadores pelos impactos e implementada pelo órgão ambiental competente (FARIA, 2008, p. 36 e p. 37).

Assim, o termo compensação financeira, objeto deste estudo, é definida como a indenização atribuída aos responsáveis pela exploração dos recursos naturais e ou pelos danos ambientais, cujo intuito é proporcionar o retorno à condição anterior. É um mecanismo para compensar o ambiente pelas externalidades negativas provocadas pela produção ( SILVA, p.1, 2007). O conceito de externalidade, também relevante para o entendimento do objeto proposto, foi apresentado por Arthur Cecil Pigou (1877-1959). Está relacionado com o princípio poluidorpagador e com a ideia da compensação financeira.

Pigou, identificou a externalidade, quando fez um estudo dos efeitos positivos e negativos gerados pelas atividades econômicas e constatou que estas atingiam outros agentes, sem que os mesmos tivessem a possibilidade de intervir para evitar os impactos, quando não participavam da tomada de decisão. Do ponto de vista econômico, sendo o mercado definido como um bem cuja produção ou o consumo gera prejuízo ao meio ambiente, esta falha de mercado será classificada como uma externalidade. Assim, a externalidade é constatada, quando o preço de equilíbrio deixa de capturar todos os benefícios e custos de uma transação de mercado e um terceiro é afetado pela produção ou consumo de um bem. Quando o efeito 
externo gera custos a um terceiro, tem-se uma externalidade negativa. Nos casos em que gera benefícios a externalidade será positiva. Especificamente para esta categoria de estudo serão observadas as externalidades da produção que afetam o meio ambiente ou seja as externalidades negativas (THOMAS \& CALLAN, 2010).

Existem diversas maneiras de resolver problemas de externalidades, dentre as quais citase: sistema fiscal-tributação; internalização da externalidade; direito de propriedade e intervenção governamental. No caso do sistema fiscal ou da tributação, defendia Pigou, que os custos gerados pelas externalidades negativas deveriam ser identificados pelo Estado, tendo como obrigatoriedade a sua intervenção, determinando ao causador uma taxa cujo valor seria equivalente ao custo da externalidade negativa gerada. Esta é uma forma de compensar os custos sociais da produção, refletindo no preço final dos produtos ou em outras palavras uma política de estado para influenciar o comportamento do agente econômico no mercado que tinha como objetivo corrigir as externalidades negativas.

O ponto de convergência entre a teoria que está por traz do princípio do poluidor pagador e de externalidade é primordialmente fazer com que os custos de proteção ambiental e de reparação dos danos causados ao meio ambiente, recaiam sobre os custos finais de produtos e serviços que estejam na origem da atividade causadora do dano ao meio ambiente. Portanto, a incorporação dos efeitos externos da atividade desenvolvida está na origem da formulação do princípio poluidor-pagador e quando internalizados pelo agente econômico passam a fazer parte do cálculo do preço final de produtos e serviços. Sob essa ótico a tendência é que se obtenha redução significativa do dano ao meio ambiente (PETER, p. 83-85, 2010).

\section{INSTRUMENTOS REGULATÓRIOS DA COMPENSAÇÃO FINANCEIRA DOS RECURSOS NATURAIS}

\section{Instrumentos das Políticas ambientais}

As teorias e concepções que se consolidaram a partir das externalidades contribuíram com a formulação de instrumentos direcionados para solucionar os problemas ambientais. Nestas formulações foram instituídos os instrumentos de natureza não econômica e os de natureza econômicos. Em sua totalidade deve-se ressaltar que a maioria das políticas ambientais combinam as duas categorias de instrumentos (PETER, 2010). 


\section{Instrumentos de Natureza não Econômica}

Este instrumento pode ser classificado na categoria de interdições, autorizações e normas são executadas por ordem administrativa ou jurídica e podem ter incidência sobre os níveis dos custos de produção e na atividade das empresas. Os instrumentos não econômicos dizem respeito as regulamentações e regimes de proibição ou autorização, de vigilância e de controle implementado pelos poderes públicos para garantir a defesa do meio ambiente.

Uma das regulamentações jurídicas, aplicada por este instrumento, visa regrar diretamente os problemas ambientais através de políticas de proteção ambiental com destaque para a qualidade ambiental, fixando os limites para emissões de poluentes ou a escolha de um determinado tipo de processo produtivo, submetido a um sistema de autorizações e de controle. Neste instrumento o controle direto se destaca como o instrumento mais difundido de política de proteção ambiental, bem como o que é melhor aceito pelas autoridades públicas legislativas ou executivas.

De acordo com FAUCHEUX \& SYLVIE (1995), as políticas de controle direto interditam certas formas de poluição, restringindo totalmente os danos ambientais ou por outro lado estabelece limites às emissões de certos poluentes. Estas também podem comportar a obrigação de adotar certos equipamentos ou técnicas tanto para a produção de bens como para a despoluição. O controle direto se constitui principalmente na forma de normas, que em relação ao meio ambiente é definida como: normas de qualidade ambiental; normas de emissão que fixam as quantidades máximas rejeitadas de um certo poluente; normas de produto e normas de procedimentos. Cabe ressaltar que a norma não tem a função de resolução das externalidades; serve apenas para preveni-las uma vez que funciona como meio para interditar ou reduzir os prejuízos causados pela ação de um agente.

\section{Instrumentos de Natureza Econômica}

Estes instrumentos são classificados como taxas, subvenções e mercado de direito de poluir e incidem diretamente sobre as atividades econômicas cujo objetivo é produzir respeitando os limites do meio ambiente, tomando como ponto de partida a correção das externalidades através da internalização para determinar o ótimo da poluição.

A internalização fiscal proposta por Pigou se constitui, em fazer pagar pelo agente emissor da poluição uma taxa igual ao montante do dano causado. Tem-se que por este 
instrumento a taxa imposta ao poluidor é fixada num montante uniforme igual ao custo marginal da poluição no ótimo, assim o lucro marginal do poluidor encontra-se reduzido do montante da taxa obtendo-se um novo lucro marginal. Aqui para determinar a taxa ótima do imposto, é necessário conhecer a curva de custo marginal dos prejuízos. A partir desta curva se determina a taxa ótima de pagamento do imposto. O poluidor submetido a esta taxa soluciona o custo da despoluição efetuada; o prejuízo residual e o imposto residual que é interpretado como uma renda paga pela utilização do meio ambiente, como preço para a poluição residual. A soma do custo da despoluição efetuada e do prejuízo residual representam a internalização total da externalidade e por sua vez a junção do prejuízo residual e do imposto residual representa o imposto pago (PETER, 2010).

A subvenção está voltada para o caso oposto ao apresentado por Pigou, isto é, está relacionada com as externalidades positivas. Coase (1960) propõe, especificamente para as externalidades negativas, dois pagamentos simétricos: pagamento compensatório do emissor à vítima e pagamento dissuasivo da vítima potencial ao emissor potencial. Esta proposição é uma negociação bilateral direta entre agentes, diferente de taxas ou de subvenções, que se respaldam por recursos do Estado, no segundo caso proposto por Coase trata-se de uma subvenção igual ao ganho social resultante da abstenção de prejudicar, desde que esta seja paga pela vítima potencial. Operacionalmente imagina-se subvencionar a despoluição, determinando uma subvenção proporcional à redução da poluição (FAUCHEUX \& SYLVIE, p. 233-239, 1995).

Por último o mercado dos direitos de poluir é classificado como um instrumento de internalização específica. De acordo com Peter (2010), neste mercado propõe-se estabelecer um conjunto de direitos de propriedades exclusivos e transferíveis, negociáveis num mercado, sobre os bens até então livres. Aqui o preço do direito de poluição fixar-se-á livremente neste mercado, possuindo todas as características de um mercado concorrencial.

A negociação estabelecida é a de que o Estado ou o órgão de tutela deste mercado, tem o entendimento da quantidade de poluição aceitável no meio ambiente através de uma norma de qualidade ambiental, e põe à venda no mercado de título os direitos de poluição, representando a quantidade de poluição correspondente a esse objetivo de qualidade. Cada possuidor destes títulos ou certificados possuem o direito a uma quantidade de poluição correspondente ao montante detido. Quanto ao resto, ele deverá despoluir, portanto a obrigatoriedade da compra do título assegura que não há poluição sem título. Desta forma está criado um mercado de título, que pode ser também considerado como um mercado de poluição, 
uma vez que os títulos representam exatamente a quantidade de poluição (FIELD \& FIELD, 2014).

Neste contexto ressalta-se que os títulos são trocados a uma cotação resultante da oferta e da procura, conforme as condições nas quais possam despoluir, os industriais poluidores comprarão ou não no mercado de títulos suplementares. Assim cada industrial poluidor tem interesse em comprar títulos até o momento em que a cotação destes direitos se iguale ao custo marginal de despoluição, além disso comprar títulos torna-se mais dispendioso que despoluir. Se houver uniformidade na ação de todos os poluidores, a cotação vai fixar-se a um nível que igualha os custos marginais de despoluição dos diferentes poluidores. Portanto as quantidades de poluição vão variar conforme as empresas, bem como as quantidades de títulos detidas. Desta forma pode-se afirmar que o custo é então mínimo para a coletividade, uma vez que cada um iguala a cotação do título ou seja o preço da poluição com o seu custo marginal de despoluição. Cada um está, portanto, situado no ótimo e desta forma o ótimo social é atingido.

Sob a ótica da externalidade, cabe destacar que a mesma é internalizada dado que a poluição possui um preço materializado pela cotação de certificado, em que os agentes podem integrar o custo da despoluição no seu cálculo econômico e que os direitos de propriedade foram especificados sobre os bens livres, direitos onde a ausência gerava a externalidade (FAUCHEUX \& SYLVIE, p. 240-241, 1995).

\section{MARCOS LEGAIS DA COMPENSAÇÃO FINANCEIRA DOS RECURSOS NATURAIS}

O agravamento da crise ambiental, originada pelos impactos econômicos, despertou a sociedade civil organizada e as instituições governamentais e não governamentais a planejar, institucionalizar e implementar um sistema de proteção, constituída por um conjunto de instrumentos; normas e políticas públicas que minimize os impactos e danos causados pela ação antrópica ao meio ambiente.

O marco legal de uma Política Pública a nível de Brasil, voltada para as preocupações com a escassez dos recursos naturais e da crise ambiental, como fruto das atividades humanas, deu-se com a Lei Federal no 6.938, de 31 de agosto de 1981, regulamentada pelo Decreto n. ${ }^{\circ}$ 99.274, de 06 de junho de 1990, que criou a Política Nacional do Meio Ambiente. É neste momento que se estabelece os objetivos, os princípios, as diretrizes, os instrumentos e as atribuições vinculadas com a utilização dos recursos naturais e as relações antrópicas. 
Neste ano também foi criado o Sistema Nacional do Meio Ambiente (SISAMA) e ficou implementada legalmente a política de preservação, melhoria e recuperação da qualidade ambiental propícia a vida, com foco nas condições de desenvolvimento socioeconômico, de segurança nacional e de proteção a dignidade humana, a partir da interação do homem com o espaço (BÃNADOS, p.15, 2011).

O autor supracitado ainda evidencia que a Lei n. ${ }^{\circ} 6.938 / 81$, implantou os meios legais para alcançar o desenvolvimento sustentável a nível de Brasil; implementou os princípios protetivos e determinantes do meio ambiente e instituiu os instrumentos públicos da política ambiental.

Um dos princípios adotados por esta política pública é o Princípio da Precaução que tem como objetivo compatibilizar o desenvolvimento econômico-social atrelado a preservação dos recursos ambientais, garantindo a utilização racional e disponibilidade permanente. Incorporou também o Poluidor-Pagador. Este princípio reforçou a imposição ao poluidor da obrigatoriedade de recuperar ou de indenizar os danos por ele causado. Determina a obtenção do padrão de eficiência, internalização dos custos sociais externos oriundos da atividade econômica e equidade social. O princípio poluidor-pagador objetiva na sua essência efetivar as obrigações econômicas às atividades causadoras de danos, para que as externalidades ambientais ou os custos de medida de proteção ao meio ambiente, incidam nos custos finais de produtos e serviços em que a origem encontra-se na produção da atividade poluidora.

A Política nacional de Meio Ambiente implementou ainda o Princípio Usuário Pagador e o Princípio da Prevenção. O primeiro foi justificado pela cobrança de um valor econômico pela utilização ou outorga do direito de uso de um recurso natural ou de um bem ambiental. Já o segundo tem como meta a precaução quanto ao dano ambiental antes da implantação de uma atividade econômica. Assim evidenciou de acordo com o direito ambiental que a cobrança e pagamento dos serviços ambientais são o princípio da prevenção e do usuário-pagador.

Outra Política Pública adotado a nível de Brasil relacionada aos recursos naturais referese a Lei n. ${ }^{\circ}$ 4.771/65 que trata do Código Florestal, o exposto nesta Lei também está reiterado na CF 88. Trata-se aqui da competência comum da União, dos Estados, do Distrito Federal e dos Municípios, relativo ao dever de preservar a fauna, a flora e as florestas.

Já a Política Pública da gestão setorial de Recursos Hídricos foi regulamentada no Brasil a princípio pelo Código de Águas no ano de 1934 e foi incorporada na CF 88 ressaltando a preservação dos recursos hídricos, seu uso e exploração. A Criação do Sistema Nacional de Gerenciamento dos Recursos Hídricos - SINGREH e da promulgação da Lei n. ${ }^{\circ}$ 9.433/97 que 
instituiu a Política Nacional de Recursos Hídricos, trouxe para o País a atualização desta Política inovando com a gestão de bacias hidrográficas, instituindo a água como um bem de domínio público e estabelecendo que a gestão dos recursos hídricos devem ser descentralizada e contar com a intervenção do poder público, dos usuários e da população, se consolidando de forma participativa e integrada. O SINGREH juntamente com os órgão e entidades gestoras da água tem por objetivos: coordenar a gestão integrada da água; arbitrar administrativamente os conflitos relacionados com os recursos hídricos; implementar a política nacional de recursos hídricos; Planejar, regular e controlar o uso, a preservação e a recuperação dos recursos hídricos e promover a cobrança pelo uso de recursos hídricos (BRASIL, 1997).

Conforme BRASIL (1997), a outorga de direitos de uso dos recursos hídricos e a compensação financeira, são algumas das inovações implementadas pela Lei n. ${ }^{\circ}$ 9.433/97 para viabilizar a implantação da Política Nacional de Recursos Hídricos. A outorga apresenta como objetivo assegurar o controle quantitativo e qualitativo do uso da água bem como o efetivo exercício dos direitos de acesso a este bem natural. Já a compensação financeira pela utilização dos recursos hídricos tem como princípio a maximização do bem-estar social, considerando as diversas formas de participação destes recursos nos processos econômicos, estando estes valores capturados ou não.

No Brasil, a Política Nacional de Meio Ambiente, também contempla os instrumentos de gestão ambiental pública chamados de instrumentos de comando e controle (regulatórios) e Instrumentos econômicos ou de mercado. Os principais mecanismos da política de comando e controle são as normas e padrões, licenças e permissões e controle do uso do solo e da água. Classificados nas categorias: padrões ambientais de qualidade e emissão; controle do uso do solo (saneamento e áreas de proteção); licenciamento, estudo de impacto ambiental (EIA), relatório de impacto ambiental (RIMA) e penalidades (multas, compensações). Aqui está expresso a ideia, de que a gestão ambiental no Brasil, está associada ao meio ambiente como um bem público, sendo o Estado responsável pela intervenção e pelas normas reguladoras.

Embora muitos autores considerem os instrumentos de comando e controle bastante eficazes, estes implicam em altos custos de implementação e podem ser injustos por tratar todos os poluidores de forma igual, ou seja não levam em consideração o tamanho da empresa e a quantidade de poluentes lançados no espaço.

Os Instrumentos econômicos ou de mercado classificados como: taxa e tarifas subsídios; certificados de emissões transacionáveis; sistemas de devolução de depósitos e 
impostos, são diretamente relacionados com a política ambiental e com a produção econômica e o meio ambiente.

Conforme apresentado por SILVA (2007), os instrumentos econômicos implementados no Brasil para aprimorar a gestão ambiental são:

\begin{abstract}
Cobrança pelo uso da água em bacias hidrográficas com o objetivo de financiar as bacias hidrográficas e indução do uso racional de recursos hídricos; Tarifa de esgoto industrial baseada no conteúdo de poluentes objetivando recuperação de custos de estações de tratamento de esgoto; compensação financeira devido a exploração dos recursos naturais: objetiva a compensação não tributária, baseada em percentual fixo das receitas brutas destas atividades para compensar municípios e estado onde se realiza a produção; Compensação fiscal por área de preservação objetiva compensar município pelas restrições de uso do solo em áreas de mananciais e de preservação florestal e taxas florestais com objetivo de financiar projetos de reflorestamento público e financiar atividades do serviço florestal do estado.
\end{abstract}

Estes instrumentos são utilizados no Brasil como política de correção ou prevenção das falhas de mercado; se vinculam ao aumento de recursos e tecnologia e promovem o aumento equitativo da renda. São também utilizados para formação de incentivos para que os agentes poluidores internalizem os custos ambientais que normalmente não seriam contabilizados em sua estrutura de custos na ausência de destes incentivos. (BAÑADOS, p.63, 64, 2011).

Outros instrumentos de políticas públicas relacionados com os recursos naturais e presentes na legislação brasileiras são: Lei no 4. 771, de 15 de setembro de 1965 que institui o Novo Código Florestal Brasileiro; Lei n ${ }^{\circ}$ 5. 197, de 3 de janeiro de 1967, Lei de Proteção da Fauna; Lei $\mathrm{n}^{\circ}$ 7.347, de 24 de julho de 1985 que disciplina a ação civil pública de responsabilidade por danos causados ao meio ambiente; Constituição Federal de 5 de outubro de 1988. Trata da proteção ao meio ambiente, no art. 225; Criação do Instituto Brasileiro de Meio Ambiente - IBAMA em 1989; Decreto nº 750, de 10 de fevereiro de 1993 dispõe sobre o corte, a exploração e a supressão da vegetação primária ou nos estágios avançados e médio de regeneração da Mata Atlântica; Decreto no 1.922, de 5 de junho de 1996 que Dispõe sobre o reconhecimento das Reservas Particulares do Patrimônio Natural (RPPN); Lei no 9.605, de 12 de fevereiro de 1998. Lei de Crimes Ambientais, no que se refere as infrações e punições; Lei $\mathrm{n}^{\circ}$ 9.985, de 18 de julho, de 2000 que Institui o Sistema Nacional de Unidade de Conservação (SNUC), trata no art. 36 do Instrumento da Compensação ambiental; Decreto $n^{\circ}$ 4.340, de 22 de agosto de 2002. Regulamenta o SNUC; Decreto $n^{\circ}$ 5.758, de 13 de abril de 2006 Estabelece o Plano Estratégico Nacional de Áreas Protegidas; Lei no 11.428, de 22 de dezembro de 2006. 
Dispõe sobre a utilização e proteção da vegetação nativa do bioma Mata Atlântica; Lei no 11,516, de 28 de agosto de 2007. Dispõe sobre a criação do Instituto Chico Mendes de Conservação da Biodiversidade- Instituto Chico Mendes - ICMBio (FARIA, p. 62, 2008).

\section{CONCLUSÕES EVIDENCIADAS}

A produção econômica resultante das relações antrópicas e dos recursos naturais, estão diretamente relacionadas com o funcionamento das políticas que garantam o desenvolvimento sustentável. No Brasil desde 1981, está regulamentada a política pública voltada para preservação, prevenção ou compensação dos danos ambientais.

Durante a pesquisa constatou-se que a compensação financeira dos recursos naturais pode ser um mecanismo utilizado para evitar a produção desordenada das externalidades negativas e por outro lado servirá como instrumento econômico que proporciona o equilíbrio equitativo do meio ambiente.

Foi também possível identificar que a categoria compensação financeira, é um campo de estudo que apresenta perspectivas positivas para novas pesquisas, porque ainda se revelou pouco explorada e com necessidade de mais literatura. Se constatou também a necessidade de elaboração de um instrumental metodológico que der suporte a avaliação desta política pública.

No âmbito da política nacional, a compensação financeira dos recursos naturais só será implantada de forma eficiente, se for resolvido muitos gargalos dentre os quais os apresentados por SILVA (2007), que são: Inexistência de clareza nos critérios econômicos de cobrança; Conflito de jurisdição na gestão dos recursos arrecadados; Incidência e alocação dos recursos não obedecem a critérios ambientais; Difícil fiscalização e acompanhamento dos resultados e Dificuldades legais para utilizar os instrumentos para fins de indução de uso.

Sendo a compensação financeira dos recursos naturais de responsabilidade dos entes federativos: União, Estados e Municípios, constatou-se que é preciso aprimorar os instrumentos de gestão pública que possibilita a execução, acompanhamento e avaliação desta política pública, para minimizar os impactos negativos decorrentes das ações antrópicas relacionadas com a produção. 


\section{REFERÊNCIAS}

ACSELRAD, Henri. 2002. Justiça ambiental e construção social do risco.

ACSELRAD; MELLO e BEZERRA. O que é justiça ambiental. - Rio de Janeiro: Garamond, 2009.

BARBIERI, José Carlos. Desenvolvimento e meio ambiente: as estratégias de mudanças da Agenda 21. - 10ª ed - Petrópolis, RJ: Vozes, 2009.

BAÑADOS, Irina Moreira da Fonseca. Políticas Públicas: Iniciativas de pagamento por serviços ambientais para preservar a água. 145p. Dissertação (Mestrado em Organizações e Desenvolvimento) - FAE Centro Universitário. Curitiba, 2011

BRASIL. Constituição (1988). Constituição da República Federativa do Brasil de 1988. Diário Oficial [da] República Federativa do Brasil. Brasília, DF, 08 out. 1998.

BRASIL. Lei ${ }^{\circ}$ 6.938, de 31 de agosto de 1981. Dispõe sobre a Política Nacional do Meio Ambiente, seus fins e mecanismos de formulação e aplicação, e dá outras providências. Diário Oficial [da] República Federativa do Brasil. Brasília, DF, 02 set. 1981

BRASIL. Lei $n^{\circ}$ 9.433, de 08 de janeiro de 1997. Institui a Política Nacional de Recursos Hídricos, cria o Sistema Nacional de Gerenciamento de Recursos Hídricos. Diário Oficial [da] República Federativa do Brasil. Brasília, DF, 09 jan. 1997.

CAVALCANTI, Clovis (Org.). Meio ambiente, desenvolvimento sustentável e políticas públicas. -2 $2^{a}$ ed. - São Paulo: Cortez: Recife, PE: Fundação Joaquim Nabuco, 1999.

CAVALCANTI, Clovis (Org.). Desenvolvimento e natureza: estudo para uma sociedade sustentável. São Paulo: Cortez: Recife, PE: Fundação Joaquim Nabuco, 1995.

DINIZ, Marco Túlio Mendonça. Condicionantes socioeconômicos e naturais para a produção do sal marinho no Brasil: as particularidades da principal região produtora. 227p. Tese (Doutorado) Universidade Estadual do Ceará, Centro de Ciências da Saúde, Programa de Pós Graduação em Geografia, Fortaleza 2013.

FARIA, Ivan Dutra. Compensação ambiental: os fundamentos e as normas; a gestão e os conflitos. 115 p. Texto para discussão 45. Coordenação de estudos consultoria legislativa do senado federal. Brasília - DF. Jul. 2008.

FAUCHEUX, Sylvie; NOEL, Jean-François. Economia dos recursos naturais e do meio ambiente. Coleção economia e política. Portugal: Instituto Piaget, 1995. 
FIELD, Barry C; FIELD, Martha K. Introdução a economia do meio ambiente - 6.ed - Porto alegre: AMGH, 2014.

MAY, Peter H. (Org.). Economia do meio ambiente. Teoria e Prática - 2.ed - Rio de Janeiro: Elsevier, $2010-4^{\mathrm{a}}$ reimpressão.

MUKAI, Toshio. Direito ambiental municipal: abordagens teóricas e práticas. Belo Horizonte: Fórum, 2010.

LEFF, Enrique. Saber ambiental: sustentabilidade, racionalidade, complexidade, poder.$8^{\mathrm{a}}$ ed. - Petrópolis, RJ: Vozes, 2011.

PEREIRA, et al. Economia e finanças públicas. $-4^{\mathrm{a}}$ ed. - Lisboa, Portugal: Escolar Editora, 2012.

SILVA, Ludimila Lima da. A compensação financeira das usinas hidrelétricas como instrumento econômico de desenvolvimento social, econômico e ambiental. 147 p. Dissertação (Mestrado em Gestão Econômica do Meio Ambiente) FACE faculdade de economia, Administração, Contabilidade e Ciências da Informação e Documentação. Brasilia - DF, 2007.

THOMAS, Janet M. E CALLAN, Scott J. Economia Ambiental: fundamentos, políticas e aplicações. São Paulo: Cengage Learning, 2010. 